\title{
Strain and strain rate echocardiographic imaging predict occurrence of atrial fibrillation in post-coronary artery bypass grafting patients
}

\author{
Gomaa Abdelrazek ${ }^{1 *}$ (D, Kareem Mandour ${ }^{2}$, Mohammad Osama ${ }^{2}$ and Khaled Elkhashab ${ }^{1}$
}

\begin{abstract}
Background: Atrial fibrillation (AF) occurs very frequently after coronary artery bypass grafting (CABG); it occurs in about 20 -edictors can be used for the dedicatio $40 \%$ of patients. It is associated with several adverse events. This study aimed to extrapolate a predictor for postoperative atrial fibrillation (POAF) occurrence which is reproducible and simple to be a part of routine echocardiography screening before CABG. This study included 89 patients scheduled for isolated coronary artery bypass surgery. History, clinical examination, and complete 2D echocardiography with LA speckle tracking analysis were done preoperatively. Patients were then followed up postsurgery for incidence of AF till discharge from the hospital. The patients were divided into 2 groups according to POAF occurrence.

Results: Patients who developed postoperative AF had older age $(P=0.0032)$ and longer hospital stay $(P=0.021)$ and higher stroke incidence but statistically non-significant (14.3\% vs 3.3\%). The POAF patients showed less peak atrial longitudinal strain (PALS) value than non-POAF patients. The left atrial strain rate values showed a significant difference with the lower left atrial systolic strain rate and less negative (higher) early diastolic strain rate and late diastolic strain rate. After multivariate logistic regression analysis, the independent predictors for POAF were PALS (OR 0.770, 95\% Cl 0.627-0.946), late LA diastolic strain rate (LASRa) (OR 3.476, 95\% Cl 1.207-12.186), and age (OR $1.181,95 \% \mathrm{Cl} 1.011-1.379)$.
\end{abstract}

Conclusion: Preoperative LA global strain assessed by 2D speckle tracking analysis could be helpful as a predictor for AF post-CABG surgery, and identification of these patients may reduce its morbidity and mortality. The study suggested PALS value less than 29.8 to be a predictor for the occurrence of POAF.

Keywords: Left atrial dysfunction, Left atrial strain, Postoperative atrial fibrillation, Speckle tracking

\section{Background}

Atrial fibrillation is a frequent complication after coronary artery bypass grafting surgery; it occurs in about 20 to $40 \%$ of patients. AF can cause hemodynamic compromise, thromboembolic complications, and prolonged hospitalization [1].

\footnotetext{
* Correspondence: gabrazek@yahoo.com

${ }^{1}$ Cardiology Department, Faculty of Medicine, Fayoum University, Faiyum, Egypt

Full list of author information is available at the end of the article
}

So, patients with a higher risk of postoperative AF (POAF) occurrence should be identified to develop prophylactic strategies in risky subjects [2]. Also, it is crucial to select patients who will benefit from good prophylactic management or intensive monitoring. Because of the limited understanding of POAF pathophysiology, no effective prophylaxis treatment has been developed yet. Multiple causes as inflammation, oxidative stress, atrial fibrosis, and changes in expression of 
atrial connexins contribute to the development of proarrhythmia [3].

The LA has a significant contribution in cardiac performance. The mechanical LA function has 3 components: (1) a reservoir function during left ventricular systole, (2) a passive conduit for transferring blood from the pulmonary veins to $L V$ during early ventricular diastole, and (3) a booster pump function with an active LA emptying during late ventricular diastole [4].

Tissue Doppler imaging (TDI) and 2D speckle tracking (strain and strain rate) for myocardial deformation are extensively used for the early detection of myocardial dysfunction with high sensitivity [5]. Left atrial enlargement and dysfunction were powerful markers for increased mortality in patients with CAD. There is a lack of literature as regards the assessment of LA function. Unlike the Doppler-derived strain and strain rate, 2DSE is angle non-dependent [6]. Assessment of LA deformation by Doppler-derived strain imaging has been used for LA function evaluation. However, this method has limited reproducibility and angle dependence and is affected by noise artifacts [7].

LA strain was a good prognostic indicator of AF recurrence after cardioversion over a 6-month follow-up, as improvement in PALS was more pronounced in patients who persisted in sinus rhythm than those with AF recurrence [8].

\section{Methods}

This is a prospective observational study that included 89 consecutive patients presenting in the period of May 2019 to August 2020 for elective CABG with normal LV ejection fraction $(>50 \%)$ and normal sinus rhythm with no history of prior attacks of AF and no valvular lesions.

Patients were subdivided into 2 groups after surgery:

Group 1 who did not develop postoperative AF (POAF)

Group 2 who developed postoperative AF (POAF)

Coronary angiography 4-12 weeks before the surgery was done for all patients. A coronary artery narrowing luminal diameter of $\geq 70 \%$ ( $\geq 50 \%$ in the left main coronary artery) was considered significant.

Exclusion criteria:

- Patients in need of valvular surgery (repair or replacement) besides CABG (including patients with moderate or higher grades of valvular lesions)

- Patients with rhythms other than normal sinus rhythm

- Patients with a previous history of AF

- History of acute coronary syndrome for less than 30 days

- Patients with right ventricular dysfunction, enlargement, or pulmonary hypertension
- Active inflammatory or infectious diseases, renal dysfunction (serum creatinine $>1.5 \mathrm{mg} / \mathrm{dL}$ ) or renal failure, COPD, and patients with hyperthyroidism or hypothyroidism

The included patients were subjected to:

- History taking, including age, sex, medications, current symptoms, any other diseases, and comorbidities

- Clinical examination, vital signs (heart rate, blood pressure), class of heart failure (NYHA class), chest pain (Canadian class), body weight measurement, and ECG for documentation of sinus rhythm

Operative and postoperative data:

- Bypass time and cross-clamping time

- Number of bypassed vessels

- Incidence of MI and stroke postoperative

- Inotropic support postoperative

- Postoperative serum potassium

- Duration of hospital stay

- Clinical follow-up data was obtained from inpatient postoperative ICU examinations

Patients were continuously monitored for 1 week after CABG for detection of POAF (any AF episode lasting more than $30 \mathrm{~s}$ ).

\section{Standard echocardiography}

Baseline 2D echocardiogram with apical 2- and 4chamber views was done with the patient in the left lateral decubitus by a single trained operator with a probe 2-4 MHz (Philips iE33 machine). The echocardiography was done in the day prior to surgery. Assessment of LV and LA diameters was done according to the current ASE (American Society of Echocardiography) recommendations. LV ejection fraction was measured using the modified biplane Simpson's method. LA volumes were measured from apical 4- and 2-chamber views using the biplane method. Pulsed-wave Doppler at the mitral valve leaflets tips in an apical 4-chamber view and tissue Doppler velocities of medial and lateral mitral annulus were used for evaluating LV diastolic function. The mitral and aortic valve opening and closure timings were assessed using pulsed-wave Doppler tracings of LV inflow and outflow and tissue Doppler.

\section{Speckle tracking}

Peak atrial longitudinal strain (PALS) was obtained from the average of values observed in all segments of the LA in 4-, 3-, and 2-chamber views. 
The graph of global and segmental SR and the numeric data both segmental and global average strain values in the "bulls-eye" format could be obtained.

In our study, the start point for processing software in strain and strain rate measurements was the peak $R$ wave in ECG monitoring. The results of the Mascot trial are consistent with the method used in our study showing that QRS measurements are more accurate than $\mathrm{P}$ wave measurements and more reproducible [9].

PALS was calculated at the termination of the reservoir phase on the strain curve (the peak positive curve value at the strain curve).

Strain rate curve for each atrial segment in the apical 4-chamber view:

The first negative deflection after R wave on ECG was E-wave (the conduit phase in early diastole).

The second negative deflection after $\mathrm{R}$ wave on ECG was A-wave (the LA contractile phase in late diastole).

Positive deflection was $\mathrm{S}$-wave (the reservoir phase during ventricular systole).

$S R E, S R A$, and $S R S$ were measured at the peak of those three waves, respectively.

To measure strain and strain rate of LA walls, offline analysis was done using Philips Q lab 10 software. The LA wall was divided into six segments from the septal mitral annulus to the lateral mitral annulus in the apical four-chamber view, first and second segments correspond to the inter-atrial septum, third and fourth segments to the roof of the LA, and fifth and sixth segments to the lateral wall. The same software used for the analysis of ventricular function was used as there is still no software for atrial strain assessment.

\section{Statistics}

Data were analyzed using Statistical Program for Social Science (SPSS) version 25 for windows (SPSS Inc., Chicago, IL, USA). Quantitative variables were presented as mean \pm standard deviation (SD). Qualitative variables were presented as percentages.

Independent-samples t-test was used when comparing two means of normally distributed variables. The chisquare $\left(\mathrm{X}^{2}\right)$ test was used to compare between two categorical variables. Fisher exact test was used in the place of the chi-square test in 2 by 2 tables.

Multivariate logistic regression was used to predict the value of a variable based on the value of two or more other variables. Receiver operating characteristic (ROC) curve analysis was used to identify optimal cut-off values. $p$-value $\leq 0.05$ was considered significant.

\section{Ethics approval and consent to participate}

Study approval was given from the ethical review committee of our Faculty before the study conduction, and every patient was assigned an informed written consent according to the principles of the Local Ethical Committee (Committee reference number: not applicable).

\section{Results}

Patients who developed AF were statistically significantly older than patients who did not develop $\operatorname{AF}(P$ value $=$ $0.032)$. There were no statistically significant differences between the 2 groups as regards gender, BMI, hypertension, diabetes, and smoking. The 2 groups showed no statistical significance in NYHA class, Canadian class, serum creatinine levels, heart rate, or the number of coronary arteries affected. Regarding the preoperative medications, there was no statistical significance except for preoperative nitrate administration (Table 1).

The operative data were nearly similar with no statistical significance between the 2 groups The postoperative data showed no statistical significance except for the hospital stay, where the no POAF group showed a longer hospital stay $(P$ value $=0.021)($ Table 2$)$.

The preoperative echocardiographic data showed several significant differences. The POAF patients had a lower mitral E velocity at mitral Doppler inflow measurements, a lower E/A ratio, and a longer mitral E DT. The tissue Doppler measurements showed a statistically lower e' value in the POAF group. Two-dimensional speckle tracking drove peak atrial longitudinal strain (PALS) showed a lower value in the POAF group. The strain rate values showed a statistical difference with a lower systolic strain rate and higher (less negative) early and late diastolic strain rates (Table 3).

For the cut-off value of LA strain and strain rate for POAF and ROC curve analysis and multivariate analysis, the only predictor variables for the POAF occurrence were age, PALS, and late atrial strain rate, and PALS of less than 29.8 is the cut-off value for the occurrence of POAF (Tables 4 and 5 and Figs. 1 and 2).

\section{Discussion}

Left atrial contractile dysfunction has been observed in CAD patients and it has been considered as a potential risk factor for the occurrence of AF [10].

Strain rate echocardiography (STE) is a feasible and reproducible tool for the objective evaluation of cardiac wall deformation [7]. STE has multiple advantages over classic Doppler-derived parameters, as it is angle nondependent and has less noise effects, dropouts, and artifacts. It is frequently used for atrial function evaluation [11], especially atrial longitudinal strain, as a good parameter for the detection of LA function in different conditions such as AF. STE and LA strain are very good tools for LA function assessment [12].

Several studies have established the association between POAF in CAD patients and LA dysfunction using TDI and 2D speckle tracking with its angle 
Table 1 Comparison between the study groups as regards the demographic data, clinical data, and medications

\begin{tabular}{|c|c|c|c|}
\hline Demographic data & No POAF & POAF & $\begin{array}{l}P- \\
\text { value }\end{array}$ \\
\hline Count & 61 & 28 & \\
\hline Age (years) & $55.0 \pm 6.4$ & $58.7 \pm 9.2$ & 0.032 \\
\hline BMI $\left(\mathrm{kg} / \mathrm{m}^{2}\right)$ & $31.5 \pm 4.1$ & $33.0 \pm 3.1$ & 0.093 \\
\hline \multicolumn{4}{|l|}{ Risk factors } \\
\hline Male gender & $40(65.6 \%)$ & $18(64.3 \%)$ & 0.906 \\
\hline HTN & $38(62.3 \%)$ & $20(71.4 \%)$ & 0.401 \\
\hline DM & $28(45.9 \%)$ & $18(64.3 \%)$ & 0.107 \\
\hline Smoking & $32(52.5 \%)$ & $16(57.1 \%)$ & 0.681 \\
\hline \multicolumn{4}{|l|}{ Clinical data } \\
\hline \multicolumn{4}{|l|}{ NYHA class } \\
\hline Class 1 & 42 (68.9\%) & 19 (67.9\%) & 0.925 \\
\hline Class 2 & 19 (31.1\%) & $9(32.1 \%)$ & \\
\hline \multicolumn{4}{|l|}{ CCS class } \\
\hline Class 1 & $23(37.7 \%)$ & $6(21.4 \%)$ & 0.723 \\
\hline Class 2 & $29(47.5 \%)$ & $21(75 \%)$ & \\
\hline Class 3 & $9(14.8 \%)$ & $1(3.6 \%)$ & \\
\hline Heart rate $($ beat $/ \mathrm{min})$ & $76.4 \pm 10.6$ & $75.5 \pm 10.8$ & 0.708 \\
\hline Creatinine (mg/dL) & $0.90 \pm 0.25$ & $0.94 \pm 0.26$ & 0.726 \\
\hline \multicolumn{4}{|l|}{ CAD type } \\
\hline Single vessel disease & $4(6.6 \%)$ & $0(0 \%)$ & 0.615 \\
\hline Two-vessel disease & $12(19.7 \%)$ & $11(39.3 \%)$ & \\
\hline Multi-vessel disease & $45(73.7 \%)$ & 17 (60.7\%) & \\
\hline \multicolumn{4}{|l|}{ Medication } \\
\hline Aspirin & $61(100 \%)$ & $28(100 \%)$ & 1.000 \\
\hline Statins & $46(75.4 \%)$ & 19 (67.9\%) & 0.456 \\
\hline Nitrates & $56(91.8 \%)$ & $16(57.1 \%)$ & $<0.001$ \\
\hline Beta blockers & $50(82 \%)$ & $20(71.4 \%)$ & 0.260 \\
\hline$C C B$ & $4(6.6 \%)$ & $2(7.1 \%)$ & 1.000 \\
\hline Digoxin & $0(0 \%)$ & $1(3.6 \%)$ & 0.315 \\
\hline Diuretic & $14(23 \%)$ & $3(10.7 \%)$ & 0.173 \\
\hline ACEI or ARB & $46(75.4 \%)$ & $18(64.3 \%)$ & 0.278 \\
\hline
\end{tabular}

independence and the ability to specify myocardial active motion and passive tethering.

In our study, the postoperative AF was $31 \%$ (28 patients of 89 patients). EXCEL trial demonstrated that new-onset AF had an 18\% rate after CABG [13]. Several studies demonstrated that postoperative AF was observed post-CABG with a frequency of 20-40\% [14].

This study showed no difference in general demography between the two groups except for age as the POAF group was significantly older which is consistent with Nevzat Erdil et al. [15], Mariscalco et al. [11], Mahoney et al. [16], and Hernandez et al. [17] findings. The POAF was similar in both genders which is
Table 2 Comparison between the study groups as regards the operative and postoperative data

\begin{tabular}{|c|c|c|c|}
\hline Operative data & No POAF & POAF & $\begin{array}{l}P \text { - } \\
\text { value }\end{array}$ \\
\hline Count & 61 & 28 & \\
\hline Cross-clamp (min) & $72.4 \pm 17.7$ & $65.2 \pm 12.6$ & 0.056 \\
\hline Bypass time (min) & $101.9 \pm 19.7$ & $94.3 \pm 10.6$ & 0.060 \\
\hline \multicolumn{4}{|l|}{ Number of grafts } \\
\hline One & $4(6.6 \%)$ & $0(0 \%)$ & 0.388 \\
\hline Two & $23(37.7 \%)$ & $11(39.3 \%)$ & \\
\hline Three or more & $34(55.7 \%)$ & $17(60.7 \%)$ & \\
\hline \multicolumn{4}{|l|}{ Postoperative data } \\
\hline K level (mmol/L) & $4.0 \pm 0.5$ & $4.0 \pm 0.5$ & 0.984 \\
\hline \multicolumn{4}{|l|}{ Cardiac supports } \\
\hline Inotropes & $42(68.9 \%)$ & $21(75 \%)$ & 0.554 \\
\hline IABP & $3(4.9 \%)$ & $4(14.3 \%)$ & 0.200 \\
\hline \multicolumn{4}{|c|}{ Postoperative complications } \\
\hline $\mathrm{Ml}$ & $8(13.1 \%)$ & $3(10.7 \%)$ & 1.000 \\
\hline Stroke & $2(3.3 \%)$ & $4(14.3 \%)$ & 0.075 \\
\hline Hospital stay (days) & $10.4 \pm 2.3$ & $11.5 \pm 1.8$ & 0.021 \\
\hline
\end{tabular}

consistent with Lee et al. [18] and in contrast to Mahoney et al. [16] who stated that male gender had a higher incidence of POAF.

Hernandez et al. [17] meta-analysis revealed that obesity had a moderate risk of developing POAF while in our study body mass index and obesity showed no statistical value. Sun et al. [19] found a relation between high BMI

Table 3 Comparison between the study groups as regards the echocardiographic measurements

\begin{tabular}{llll}
\hline Echocardiographic data & $\begin{array}{l}\text { No POAF } \\
\text { Mean } \pm \text { SD }\end{array}$ & $\begin{array}{l}\text { POAF } \\
\text { Mean } \pm \text { SD }\end{array}$ & P-value \\
\hline LVEDD (mm) & $52.8 \pm 4.8$ & $51.7 \pm 5.9$ & 0.352 \\
LVESD (mm) & $34.5 \pm 4.7$ & $34.2 \pm 4.9$ & 0.785 \\
LVEF (\%) & $61.8 \pm 7.9$ & $61.5 \pm 5.3$ & 0.879 \\
LA diameter (mm) & $36.3 \pm 3.3$ & $37.1 \pm 2.5$ & 0.219 \\
Mitral E velocity (cm/s) & $70.7 \pm 17.7$ & $55.8 \pm 10.6$ & $<0.001$ \\
Mitral A velocity (cm/s) & $68.7 \pm 18.3$ & $68.6 \pm 17.4$ & 0.988 \\
Mitral E/A & $1.07 \pm 0.35$ & $0.89 \pm 0.38$ & 0.025 \\
Mitral E' velocity (cm) & $7.1 \pm 2.4$ & $5.5 \pm 2.1$ & 0.003 \\
Mitral A' velocity (cm) & $8.4 \pm 2.2$ & $8.9 \pm 1.4$ & 0.310 \\
Mitral S' velocity (cm) & $7.0 \pm 1.6$ & $6.8 \pm 1.4$ & 0.373 \\
Mitral E/E' & $10.6 \pm 2.8$ & $11.2 \pm 3.2$ & 0.413 \\
Mitral E deceleration (ms) & $201.6 \pm 38.9$ & $236.0 \pm 27.8$ & $<0.001$ \\
PALS (\%) & $32.9 \pm 5.9$ & $25.6 \pm 6.1$ & $<0.001$ \\
LASRs (s ${ }^{-1}$ ) & $1.90 \pm 0.71$ & $1.27 \pm 0.56$ & $<0.001$ \\
LASRe (s ${ }^{-1}$ ) & $-1.69 \pm 0.60$ & $-1.00 \pm 0.45$ & $<0.001$ \\
LASRa (s ${ }^{-1}$ ) & $-2.21 \pm 0.59$ & $-1.21 \pm 0.48$ & $<0.001$ \\
\hline & & & \\
\hline & & & \\
& & &
\end{tabular}


Table 4 The cut-off value of LA strain and strain rate for POAF and ROC curve analysis

\begin{tabular}{|c|c|c|c|c|c|c|c|}
\hline Cut-off value & $\begin{array}{l}\text { SN \% } \\
(95 \% \mathrm{Cl})\end{array}$ & $\begin{array}{l}\text { SP \% } \\
(95 \% \mathrm{Cl})\end{array}$ & $\begin{array}{l}\text { PPV \% } \\
(95 \% \mathrm{Cl})\end{array}$ & $\begin{array}{l}\text { NPV \% } \\
(95 \% \mathrm{Cl})\end{array}$ & $\begin{array}{l}\text { Accuracy \% } \\
(95 \% \mathrm{Cl})\end{array}$ & $\begin{array}{l}\text { AUC } \\
(95 \% \mathrm{Cl})\end{array}$ & $P$-value \\
\hline PALS (\%) $\leq 29.8$ & $\begin{array}{l}82.1 \% \\
(63.1-93.9)\end{array}$ & $\begin{array}{l}80.3 \% \\
(68.2-89.4)\end{array}$ & $\begin{array}{l}65.7 \% \\
(47.8-80.9)\end{array}$ & $\begin{array}{l}90.7 \% \\
(79.7-96.9)\end{array}$ & $\begin{array}{l}80.9 \% \\
(71.2-88.5)\end{array}$ & $\begin{array}{l}0.800 \\
(0.667-0.884)\end{array}$ & $<0.001$ \\
\hline $\operatorname{LASRs}\left(\mathrm{s}^{-1}\right) \leq 1.6$ & $\begin{array}{l}78.6 \% \\
(59.1-91.7)\end{array}$ & $\begin{array}{l}65.6 \% \\
(52.3-77.3)\end{array}$ & $\begin{array}{l}51.2 \% \\
(35.5-66.7)\end{array}$ & $\begin{array}{l}87 \% \\
(73.7-95.1)\end{array}$ & $\begin{array}{l}69.7 \% \\
(59.0-79.0)\end{array}$ & $\begin{array}{l}0.749 \\
(0.622-0.838)\end{array}$ & $<0.001$ \\
\hline $\operatorname{LASRe}\left(\mathrm{s}^{-1}\right) \leq-1.36$ & $\begin{array}{l}82.1 \% \\
(63.1-93.9)\end{array}$ & $\begin{array}{l}73.8 \% \\
(60.9-84.2)\end{array}$ & $\begin{array}{l}59 \% \\
(42.1-74.4)\end{array}$ & $\begin{array}{l}90 \% \\
(78.2-96.7)\end{array}$ & $\begin{array}{l}76.4 \% \\
(66.2-84.8)\end{array}$ & $\begin{array}{l}0.824 \\
(0.710-0.896)\end{array}$ & $<0.001$ \\
\hline $\operatorname{LASRa}\left(s^{-1}\right) \leq-1.67$ & $\begin{array}{l}85.7 \% \\
(67.3-96.0)\end{array}$ & $\begin{array}{l}90.2 \% \\
(79.8-96.3)\end{array}$ & $\begin{array}{l}80 \% \\
(61.4-92.3)\end{array}$ & $\begin{array}{l}93.2 \% \\
(83.5-98.1)\end{array}$ & $\begin{array}{l}88.8 \% \\
(80.3-94.5)\end{array}$ & $\begin{array}{l}0.908 \\
(0.810-0.957)\end{array}$ & $<0.001$ \\
\hline
\end{tabular}

ROC curve receiver operating characteristic curve, $S N$ sensitivity, $S P$ specificity, $P P V$ positive predictive value, NPV negative predictive value, $A U C$ area under the curve, $95 \%$ Cl $95 \%$ confidence interval

and incidence of POAF with an incidence of $50 \%$ of occurrence in BMI 35-40 (severely obese), but they found no correlation between normal-overweight BMI and POAF which is consistent with our study (mean BMI in our study is $32.0 \pm 3.8$ ).

Regarding other risk factors, both groups were the same regarding hypertension, diabetes, or smoking with no statistical significance which is consistent with what Nevzat Erdil et al. [15] concluded after performing 1040 isolated CABG surgeries and following up for POAF, in contrast to what Kalus et al. [2] found in their sub-study indicating that DM and postoperative use of NSAIDs predict the occurrence of POAF.

Regarding the preoperative data, both groups were nearly equal regarding NYHA class, Canadian classification, number of vessels affected, and preoperative medications which is consistent with Nevzat Erdil et al. [15] and Luigi Gabrielli et al. [20] findings.

Surprisingly, the administration of preoperative nitrates showed a better outcome on the occurrence of POAF. $91.8 \%$ of the no POAF group were on preoperative nitrates while only $57.1 \%$ of the POAF group were on preoperative nitrates. The preoperative nitrate administration was not studied before, while the postoperative nitrate administration with the inotropes and antiplatelets showed an increased risk for POAF as showed by Efird et al. [21].

Regarding the intraoperative data, both groups showed no statistical significance regarding the time cross- clamp, bypass duration, and number of grafts which is consistent with Nevzat Erdil et al. [15] results. These results were contradicted by an Indian study by Dave et al. [22] conducted on 150 patients and showed that patients with cross-clamp duration of more than $1 \mathrm{~h}$ and bypass duration of more than 100 min showed a statistically significant higher value of POAF. But these results might have been different on a larger scale like Nevzat Erdil et al. [15] (1040 patients).

In the postoperative period, the POAF group showed a higher incidence for stroke $(14.3 \%$ vs $3.3 \%$ in the no POAF group) and a longer hospital stay (11.5 \pm 1.8 vs $10.4 \pm 2.3$ in no POAF) in agreement with Nevzat Erdil et al. [15] and Echahidi et al. [23] who report that POAF lengthens hospital stay by 4.9 days mostly due to these patients had attempts to restore sinus or control of heart rate and begin and control of anticoagulants beside association between $\mathrm{AF}$ and other morbidities [23].

The postoperative use of inotropes did not increase the incidence of POAF in this study, contrary to Efird et al. [21] findings. They deduced that patients on perioperative inotropic medications have a higher incidence of POAF especially when adding nitrates and antiplatelets. He built his hypothesis on the assumption that nitrates if added to antiplatelet decrease the formation of guanosine monophosphate, so increases free radicals, catecholamines, and plasma volume.

In the preoperative echocardiographic data, both groups showed similar left ventricular end-diastolic,

Table 5 Multivariate regression analysis for incidence of POAF

\begin{tabular}{|c|c|c|c|c|}
\hline \multirow[t]{2}{*}{ Variable } & \multirow{2}{*}{$\begin{array}{l}\text { Adjusted } \\
\text { OR }\end{array}$} & \multicolumn{2}{|c|}{ 95\% confidence interval for OR } & \multirow{2}{*}{$\begin{array}{l}P \text { - } \\
\text { value }\end{array}$} \\
\hline & & Lower bound & Upper bound & \\
\hline Age (years) & 1.181 & 1.011 & 1.379 & 0.036 \\
\hline Nitrates not used & 0.069 & 0.004 & 1.170 & 0.064 \\
\hline PALS (\%) & 0.770 & 0.627 & 0.946 & 0.013 \\
\hline LASRs $\left(s^{-1}\right)$ & 0.855 & 0.151 & 4.829 & 0.859 \\
\hline $\operatorname{LASRe}\left(\mathrm{s}^{-1}\right)$ & 0.434 & 0.009 & 19.856 & 0.669 \\
\hline $\operatorname{LASRa}\left(\mathrm{s}^{-1}\right)$ & 3.476 & 1.207 & 12.186 & 0.022 \\
\hline
\end{tabular}




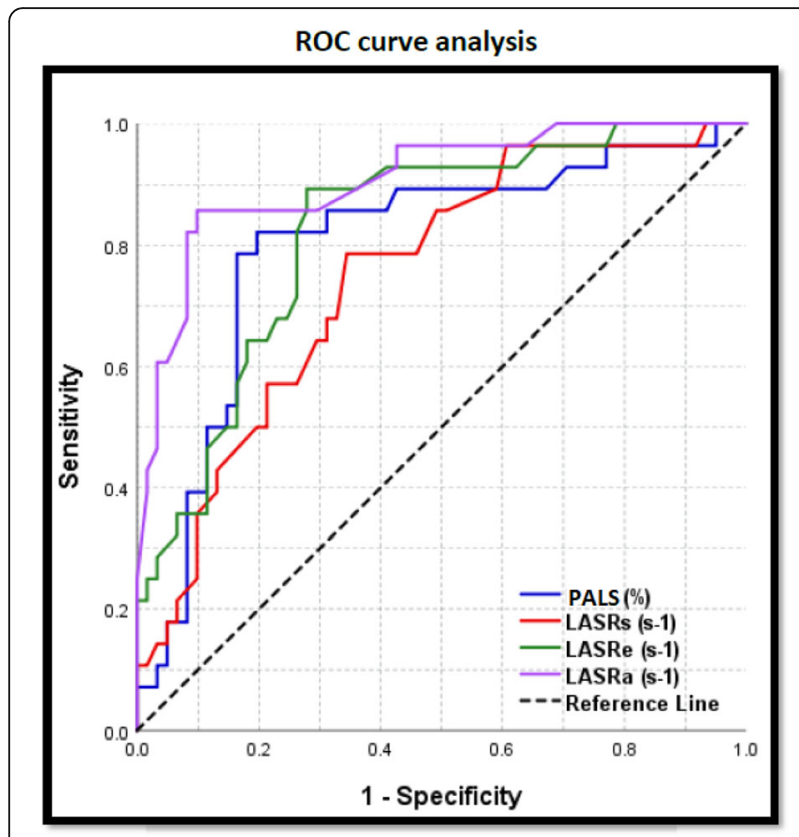

Fig. 1 ROC curve analysis

end-systolic diameters and ejection fraction. The left atrial diameters were similar in both groups in contrast to the findings of Luigi Gabrielli [20], who found that POAF has larger left atrial diameters.

The peak atrial longitudinal strain (PALS) data were consistent with Luigi Gabrielli [20], Hirose et al. [7], Verdejo et al. [22], and Her et al. [24] studies. All of these studies suggested that PALS is highly significant in predicting POAF. The strain rate data had some controversies; our study showed that the strain rate values showed statistical difference with a lower systolic strain rate (LASR) and higher (less negative) early LASRe and late LASRa diastolic strain rates, while Luigi Gabrielli, [20], Hirose et al. [7], and Verdejo et al. [22] results showed the significance of the systolic strain rate (LASRs) and late LASRa diastolic strain rate only.

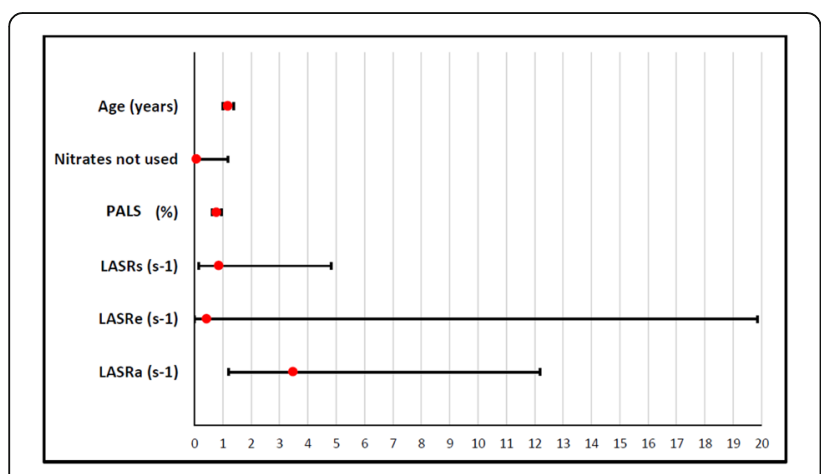

Fig. 2 Multivariate regression analysis for incidence of POAF
In our study, the POAF patients showed significantly lower peak atrial longitudinal strain value than nonPOAF patients $(25.6 \pm 6.1$ vs $32.9 \pm 5.9)$. The left atrial strain rate values showed significant difference with lower left atrial systolic strain rate $(1.27 \pm 0.56$ vs $1.9 \pm$ 0.71 ) and less negative (higher) early diastolic strain rate $(-1.0 \pm 0.45$ vs $-1.69 \pm 0.6)$ and late diastolic strain rate $(-1.21 \pm 0.48$ vs $-2.21 \pm 0.59)$.

After multivariate analysis in our study, the independent predictors for POAF were peak atrial longitudinal strain (PALS) (OR 0.770, 95\% CI 0.627-0.946), LASRa (OR 3.476, 95\% CI 1.207-12.186), and age (OR 1.181, 95\% CI 1.011-1.379). In contrast to Luigi Gabrielli et al. [20] who showed in their study that the independent predictors for POAF were age, LASRs, and LASRa [20], Hirose et al. [7] and Verdejo et al. [22] both found that age and PALS were the predictors of POAF.

So PALS was found to be a simple, reproducible, single step, and easily detected predictor of the occurrence of POAF after CABG.

\section{Conclusion}

- Multiple predictors can be used for the detection of POAF, e.g., age.

- New-onset AF post-CABG is linked to LA dysfunction when assessed by preoperative $2 \mathrm{D}$ speckle tracking echocardiography.

- Strain and strain rate showed to be an applicable method for the prediction of POAF, and due to the technical difficulties of the strain rate measurements, speckle tracking-derived strain curve shows to be a simple and single-step approach to the detection of the POAF.

- PALS of less than 29.8 could be suggested as a cut-off value for the occurrence of POAF, but it needs further studies with larger numbers.

\section{Study limitations}

- The small sample size and short period of follow-up.

- As the study is based on echocardiography, so image quality and operator experience have a great influence on the results.

- The software of the left ventricle had been used for the analysis of LA strain.

- Continuous monitoring was done only in the critical care unit and in the postoperative ward; ECG was done every $12 \mathrm{~h}$ or symptoms appear. So any undetected or transient episode of AF could be missed.

- Postoperative LA function could not be assessed as it is difficult to obtain good images for analysis. 
- The accuracy of LA strain was not compared with the invasive assessment method or non-invasive method such as CMR.

\begin{abstract}
Abbreviations
2D: 2-Dimensional; AF: Atrial fibrillation; ASE: American Society of Echocardiography; BMI: Body mass index; CABG: Coronary artery bypass grafting; CAD: Coronary artery disease; CMR: Cardiac magnetic resonance imaging; COPD: Chronic obstructive airway disease; DM: Diabetes mellitus; DT: Deceleration time; LA: Left atrium; LAS: Left atrial strain; PALS: Peak atrial longitudinal strain; STE: Speckle tracking echocardiography
\end{abstract}

\section{Acknowledgements}

Not applicable

\section{Authors' contributions}

GA was involved in collecting and analyzing the data and in preparing and editing the manuscript. KM was involved in collecting and analyzing the data. $\mathrm{MO}$ was involved in analyzing the data. KE was involved in analyzing the data and supervision. All authors have read and approved the final manuscript.

\section{Funding}

Not applicable

\section{Availability of data and materials}

The data sets used and/or analyzed during the current study are available from the corresponding author on reasonable request.

\section{Declarations}

\section{Ethics approval and consent to participate}

Study approval was obtained from the ethical review committee of the Faculty of Medicine, Fayoum University, Egypt, in January 2019 prior to the study conduction, and an informed written consent was obtained from each patient according to the rules of the Local Ethical Committee (Committee reference number: not applicable).

\section{Consent for publication}

Not applicable

\section{Competing interests}

The authors declare that they have no competing interests.

\section{Author details}

${ }^{1}$ Cardiology Department, Faculty of Medicine, Fayoum University, Faiyum, Egypt. ${ }^{2}$ National Heart Institute, Cairo, Egypt.

Received: 19 February 2021 Accepted: 21 June 2021 Published online: 03 July 2021

\section{References}

1. Maesen B et al (2012) Post-operative atrial fibrillation: a maze of mechanisms. Europace 14(2):159-174

2. Villareal RP, Hariharan R, Liu BC, Kar B, Lee W, Elayda MA, Lopez JA, Rasekh A, Wilson JM, Massumi A (2004) Postoperative atrial fibrillation and mortality after coronary artery bypass surgery. J Am Coll Cardiol 43(5):742-748. https://doi.org/10.1016/j.jacc.2003.11.023

3. Burashnikov A, Antzelevitch C (2017) Pathophysiology of atrial fibrillation. In: Kowey P et al (eds) Cardiac arrhythmias, pacing and sudden death, 1st edn. Springer, USA, pp 15-25

4. Pagel PS, Kehl F, Gare M, Hettrick DA, Kersten JR, Warltier DC (2003) Mechanical function of the left atrium: new insights based on analysis of pressure-volume relations and Doppler echocardiography. Anesthesiology 98(4):975-994. https://doi.org/10.1097/00000542-200304000-00027

5. Marwick TH et al (2006) Measurement of strain and strain rate by echocardiography. JACC 47(7):1313-1327. https://doi.org/10.1016/.jacc.2005.11.063

6. Cameli M, Mandoli GE, Loiacono F, Sparla S, lardino E, Mondillo S (2016 Oct 1) Left atrial strain: a useful index in atrial fibrillation. Int J Cardiol 220:208213. https://doi.org/10.1016/j.ijcard.2016.06.197

7. Hirose $T$ et al (2011) Left atrial function assessed by speckle tracking echocardiography as a predictor of new-onset non-valvular atrial fibrillation: results from a prospective study in 580 adults. Eur Heart J Cardiovasc Imaging 13(3):243-250

8. Shaikh AY, Maan A, Khan UA, Aurigemma GP, Hill JC, Kane JL, Tighe DA, Mick E, McManus DD (2012) Speckle echocardiographic left atrial strain and stiffness index as predictors of maintenance of sinus rhythm after cardioversion for atrial fibrillation: a prospective study. Cardiovasc Ultrasound 10(1):48. https://doi.org/10.1186/1476-7120-10-48

9. Cameli M, Miglioranza MH, Magne J, Mandoli GE, Benfari G, Ancona R, Sibilio G, Reskovic Luksic V, Dejan D, Griseli L, van de Heyning CM, Mortelmans P, Michalski B, Kupczynska K, di Giannuario G, Devito F, Dulgheru R, llardi F, Salustri A, Abushahba G, Morrone D, Fabiani I, Penicka M, Katbeh A, Sammarco G, Esposito R, Santoro C, Pastore MC, Comenale Pinto S, Kalinin A, Pičkure Ž, Ažman Juvan K, Zupan Mežnar A, Coisne A, Coppin A, Opris MM, Nistor DO, Paakkanen R, Biering-Sørensen T, Olsen FJ, Lapinskas T, Vaškelyté JJ, Galian-Gay L, Casas G, Motoc Al, Papadopoulos CH Loizos S, Ágoston G, Szabó I, Hristova K, Tsonev SN, Galli E, Vinereanu D, Mihaila Baldea S, Muraru D, Mondillo S, Donal E, Galderisi M, Cosyns B, Edvardsen T, Popescu BA (2020 Nov 13) Multicentric atrial strain comparison between two different modalities: MASCOT HIT study. Diagnostics (Basel) 10(11):946. https://doi.org/10.3390/diagnostics10110946

10. Yu CM, Fung JW, Zhang Q et al (2005) Tissue Doppler echocardiographic evidence of atrial mechanical dysfunction in coronary artery disease. Int J Cardiol 105(2):178-185. https://doi.org/10.1016/.jijcard.2004.12.077

11. Mariscalco G, Biancari F, Zanobini M, Cottini M, Piffaretti G, Saccocci M, Banach M, Beghi C, Angelini GD (2014) Bedside tool for predicting the risk of postoperative atrial fibrillation after cardiac surgery: the POAF score. J Am Heart Assoc 3(2):e000752. https://doi.org/10.1161/JAHA.113.000752

12. Voigt JU et al (2015) Definitions for a common standard for 2D speckle tracking echocardiography: consensus document of the EACV/ASE Industry Task Force to standardize deformation imaging. Eur Heart I Cardiovasc Imaging 16:1-11

13. Kosmidou I, Chen S, Kappetein AP et al (2018) New-onset atrial fibrillation after PCl or CABG for left main disease: the EXCEL trial. J Am Coll Cardiol. 71(7):739-748. https://doi.org/10.1016/j.jacc.2017.12.012

14. Kirchhof $P$ et al (2016) ESC guidelines for the management of atrial fibrillation. Eurheartj 38(7):2893-2962

15. Erdil $\mathrm{N}$ et al (2014) Predictors of postoperative atrial fibrillation after onpump coronary artery bypass grafting: is duration of mechanical ventilation time a risk factor? Ann Thorac Cardiovasc Surg 20(2):135-142. https://doi. org/10.5761/atcs.oa.12.02104

16. Mahoney EM, Thompson TD, Veledar E et al (2002) Cost-effectiveness of targeting patients undergoing cardiac surgery for therapy with intravenous amiodarone to prevent atrial fibrillation. J Am Coll Cardiol 40:737-745

17. Hernandez AV, Kaw R, Pasupuleti V, Bina P, loannidis JP, Bueno H, Boersma E, Gillinov M, Cardiovascular Meta-Analyses Research Group (2013) Association between obesity and postoperative atrial fibrillation in patients undergoing cardiac operations: a systematic review and meta-analysis. Ann Thorac Surg 96(3):1104-1116. https://doi.org/10.1016/ j.athoracsur.2013.04.029

18. Lee SH, Lee H, Park JK, Uhm JS, Kim JY, Pak HN, Lee MH, Yoon HG, Joung B (2017) Gender difference in the long-term clinical implications of new-onset atrial fibrillation after coronary artery bypass grafting. Yonsei Med J 58(6): 1119-1127. https://doi.org/10.3349/ymj.2017.58.6.1119

19. Sun X, Boyce SW, Hill PC, Bafi AS, Xue Z, Lindsay J, Corso PJ (2011) Association of body mass index with new-onset atrial fibrillation after coronary artery bypass grafting operations. Ann Thorac Surg 91(6):18521858. https://doi.org/10.1016/j.athoracsur.2011.03.022

20. Luigi Gabrielli MD, Ramon Corbalan MD, C'ordova S et al (2011) Left atrial dysfunction is a predictor of postcoronary artery bypass atrial fibrillation: association of left atrial strain and strain rate assessed by speckle tracking. Echocardiography 28(10):1104-1108

21. Efird JT, Jindal C, Kiser AC, Akhter SA, Crane PB, Kypson AP, Sverdlov AL, Davies SW, Kindell LC, Anderson EJ (2018) Increased risk of atrial fibrillation among patients undergoing coronary artery bypass graft surgery while receiving nitrates and antiplatelet agents. J Int Med Res 46(8):3183-3194. https://doi.org/10.1177/0300060518773934

22. Verdejo HE, Becerra E, Zalaquet $R$, del Campo A, Garcia L, Troncoso R, Chiong M, Marin A, Castro PF, Lavandero S, Gabrielli L, Corbalán R (2016) Atrial function assessed by speckle tracking echocardiography is a good predictor of postoperative atrial fibrillation in elderly patients. Echocardiography. 33(2):242-248. https://doi.org/10.1111/echo.13059 
23. Echahidi N, Pibarot P, O'Hara G, Mathieu P (2008) Mechanisms, prevention, and treatment of atrial fibrillation after cardiac surgery. J Am Coll Cardiol 51(8):793-801. https://doi.org/10.1016/j.jacc.2007.10.043

24. Her AY, Kim JY, Kim YH, Choi EY, Min PK, Yoon YW, Lee BK, Hong BK, Rim SJ, Kwon HM (2013) Left atrial strain assessed by speckle tracking imaging is related to new-onset atrial fibrillation after coronary artery bypass grafting. Can J Cardiol 29(3):377-383. https://doi.org/10.1016/j.cjca.2012.06.006

\section{Publisher's Note}

Springer Nature remains neutral with regard to jurisdictional claims in published maps and institutional affiliations.

\section{Submit your manuscript to a SpringerOpen ${ }^{\circ}$ journal and benefit from:}

- Convenient online submission

- Rigorous peer review

- Open access: articles freely available online

- High visibility within the field

- Retaining the copyright to your article

Submit your next manuscript at $\boldsymbol{\nabla}$ springeropen.com 